\title{
Encapsulated alizarin red species: The role of the sol-gel route on the interaction with silica matrix
}

\author{
Larissa Brentano Capeletti a , João Henrique Z. Dos Santos a,*, Edwin Moncada ${ }^{\text {b }}$, \\ Zenis N. Da Rocha ${ }^{c}$, Iuri Muniz Pepe ${ }^{\mathrm{d}}$ \\ a Instituto de Química, UFRGS, Av. Bento Gonçalves, 9500, Porto Alegre, Brazil \\ b Instituto Tecnológico Metropolitano, Robledo, Calle 73 \# 76 A 354, bloque F, Medellín, Colombia \\ c Instituto de Química, Universidade Federal da Bahia, Campus de Ondina, 40170-290, Salvador, Brazil \\ d Instituto de Fisica, Universidade Federal da Bahia, Campus de Ondina, 40210-340, Salvador, Brazil
}

\section{A R T I C L E I N F O}

\section{Article history:}

Received 24 August 2012

Received in revised form 22 December 2012

Accepted 18 January 2013

Available online 24 January 2013

\section{Keywords:}

Voltammetry

Alizarin red

Silica

Sol-gel

Encapsulation

\begin{abstract}
A B S T R A C T
Solid acid-base sensors were prepared by encapsulating alizarin red $\mathrm{pH}$ indicator within a silica matrix using the sol-gel method with four different routes: (1) non-hydrolytic, (2) acid catalyzed, (3) basic catalyzed and (4) without catalyst hydrolytic. The silica-indicator interactions in the resulting materials were investigated by cyclic and differential pulse voltammetry. Ultraviolet-visible photoacoustic spectroscopy was also employed in the characterization. The absorption band shift (49 to $72 \mathrm{~nm}$, depending on the route) between neat alizarin and alizarin encapsulated within the silica network was observed. The electrochemical behavior and the $\mathrm{pH}$ indicator interactions with the silica network were dependent on the nature of the employed sol-gel route. For the sensors prepared by the acid and hydrolytic (without catalyst) routes, the interactions with the silica network occurred through alizarin red hydroxyl groups. For the basic route, different cathodic and anodic peaks were observed depending on the $\mathrm{pH}$, suggesting different phenomena during preparation or analysis. In the non-hydrolytic route, it is possible that the quinone form of alizarin red was consumed during the process. The voltammetric results were related to the sensor performance, whereby the acid route produced a solid sensor with the shortest response time, probably because alizarin structure was preserved after the synthetic process.
\end{abstract}

(c) 2013 Elsevier B.V. All rights reserved.

\section{Introduction}

Sol-gel derived materials have received particular interest as chemical receptor matrices due to their optic transparency, mechanical stability, chemical resistance and flexibility of sensor morphological configurations [1-3]; therefore, these materials have potential application in the pharmaceutical, food and chemical industries, among others $[4,5]$.

Among sol-gel derived materials, silica represents one of the most commonly studied matrices for entrapping sensor and/or receptor molecules. The encapsulation is aimed at improving characteristics and properties of sensors such as selectivity, sensitivity, accuracy, response time and useful life, which broaden the scope of sensor applications [6], which includes $\mathrm{pH}$ measurement $[2,7,8]$; detection of gases $[9,10]$, ionic species $[11,12]$ and biomolecules such as sugars; as well as other applications in the food industry $[4,13,14]$.

However, the behavior of encapsulated molecules in silica is poorly understood because of the difficulties in receptor-matrices interaction analysis. In most cases, the amount of encapsulated receptors is very

\footnotetext{
* Corresponding author. Tel.: +55 513316 7238; fax: +55 5133167304

E-mail address: jhzds@iq.ufrgs.br (J.H.Z. Dos Santos).
}

low. For instance, in the case of encapsulated $\mathrm{pH}$ indicators, the loadings are between 4 and $18 \mu \mathrm{mol}$ of indicator per $\mathrm{g}$ of silica $[15,16]$. Therefore, characterization via routine techniques such as infrared spectroscopy (FT-IR) is often unsuccessful if the detection limit is around $1 \mathrm{wt} . \%$. In a previous study, the effect of the sol-gel route on the characteristics of acid-base sensors prepared with three different indicators [16] was studied. Nevertheless, the use of analytical techniques such as FT-IR and diffuse reflectance spectroscopy in the UV-vis region was not capable of analyzing the interaction of the $\mathrm{pH}$ indicators with the silica network. Even Raman spectroscopy, a more sensitive technique, was unsuccessful in characterizing this interaction, providing only information about the xerogel structure.

In an attempt to find some clues about the indicator-silica interaction, the use of cyclic (CV) and differential pulse voltammetry (DPV) was investigated here in an attempt to infer about it. Voltammetric techniques are known to be more sensitive than routine spectroscopic techniques. Pulse voltammetry, in which signals are more prominent due to derivation of the signals [17], is particularly sensitive. Such techniques are usually employed in evaluating the electrochemical behavior of isolated receptor molecules, that is, by describing the anodic and cathodic peaks and their respective processes of oxidation and reduction [18-21]. Moreover, they also have been employed to evaluate the 
interactions between encapsulation and immobilization matrices and the receptor or immobilized molecules [15,22,23].

The electrochemical behavior of alizarin red S (Scheme 1 ) has been well described in the literature $[18,19,21]$. It has been reported that the cathodic process corresponds to a reversible 2-electron reduction, while the anodic one, although also it also involves two electrons, is irreversible. Furthermore, such reactions are shown to be $\mathrm{pH}$ dependent [21]. On the other hand, alizarin red (Scheme 1), also simply called Alizarin, is less studied, and its interaction with a silica network has not been investigated by any technique, including voltammetry.

One approach to encapsulate molecules within silica networks is based on the sol-gel method. Sol-gel processes allow the synthesis of solid materials by gelation from a liquid reaction medium, where the oxide net is created by progressive polycondensation reactions of molecular precursors. The materials are obtained via formation of a sol, gelation of the sol and, finally, removal of the solvent. This method is considered a soft chemical approach for the synthesis of amorphous oxide materials in comparison to crystallization and precipitation methods [24]. In the hydrolytic routes, the gelling process can be accelerated with the use of acid or basic catalysts, which can affect the hydrolysis and condensation reaction differently and thus generate materials with different morphologies and textures. In the non-hydrolytic sol-gel route, i.e., in the absence of water in the medium, a metal halide reacts with an alkoxysilane catalyzed by a Lewis acid, forming a tridimensional oxide net $[25,26]$.

Therefore, in the present study, the electrochemical behavior of alizarin red $(\mathrm{AL})$ is reported as a function of $\mathrm{pH}$, along with its interactions with the silica network generated through its encapsulation via four sol-gel processes, namely hydrolytic acid-catalyzed, hydrolytic base-catalyzed, hydrolytic without catalyst and non-hydrolytic sol-gel processes. The resulting systems were characterized by cyclic voltammetry (CV), differential pulse voltammetry (DPV) and ultraviolet-visible photoacoustic spectrometry (UV-PAS) to evaluate the behavior of alizarin red in the silica networks created by these different methods. The interactions of alizarin red in this matrix may influence its electroactivity and interactions with silica under the different conditions of synthesis, including $\mathrm{pH}$ and whether the medium is hydrolytic.

\section{Material and methods}

\subsection{Materials}

Tetraethoxysilane $\left(\mathrm{Si}\left(\mathrm{OCH}_{2} \mathrm{CH}_{3}\right)_{4}\right.$, TEOS, Merck, >98\%) and silicon tetrachloride $\left(\mathrm{SiCl}_{4}\right.$, Sigma-Aldrich, 99\%) were used as received. The acid-base indicator alizarin red (AL, 97\%) (1) was provided by Sigma Aldrich. Hydrochloric acid ( $\mathrm{HCl}, 38 \%$, by Nuclear), ammonium hydroxide $\left(\mathrm{NH}_{4} \mathrm{OH}, 29 \%\right.$, by Nuclear) and $\mathrm{FeCl}_{3}(98 \%$, Merck) were employed as catalysts. High purity graphite was provided by Fisher Scientific, and buffer solutions were prepared with sodium tetrafluoroborate $\left(\mathrm{NaBF}_{4}\right.$,
Aldrich, 98\%), acetic acid $\left(\mathrm{CH}_{3} \mathrm{COOH}\right.$ glacial, Merck, $\left.100 \%\right)$, phosphoric acid $\left(\mathrm{H}_{3} \mathrm{PO}_{4}\right.$, Merck, $\left.85 \%\right)$ and boric acid $\left(\mathrm{H}_{3} \mathrm{BO}_{3}\right.$, Merck, 99.9\%).

\subsection{Synthesis of sensors by sol-gel process}

Four different routes were employed to prepare the sensors by the sol-gel process from TEOS as a raw material, following procedures already described in the literature $[23,27,28]$. The acid-base indicator employed was alizarin red (AL), and the four routes employed are acid-catalyzed (AR), base-catalyzed (BR), non-catalyzed (NCR) and non-hydrolytic (NHR) routes. The acid route was catalyzed by hydrochloric acid in a 1:20 ( $\mathrm{HCl}$ :TEOS) ratio [27]. The basic route was catalyzed by ammonium hydroxide in a 1:1 ratio $\left(\mathrm{NH}_{4} \mathrm{OH}\right.$ : TEOS) [28]. The hydrolytic non-catalyzed route was exactly the same as the acid-catalyzed route but without the addition of $\mathrm{HCl}$. The non-hydrolytic route employed TEOS and $\mathrm{SiCl}_{4}$ and was catalyzed by $\mathrm{FeCl}_{3}$ (0.5 wt.\% of final product weight) [23]. The amount of acidbase indicators was $0.1 \mathrm{~mol} \%$, corresponding to the total amount of alkoxide groups.

\subsubsection{AR method}

The sensor (powder) obtained by acid route was prepared by an aqueous solution of acid-base indicator, to which the catalyst $\mathrm{HCl}$ and TEOS were added under stirring at room temperature. The resulting solution was further stirred up to gelation taking ca. $4 \mathrm{~h}$.

\subsubsection{NCR method}

In the case of the non-catalyzed route, the preparation method was practically the same as the acid one. The sensor was obtained from an aqueous solution of AL, to which TEOS was added under stirring at room temperature. Gelation took $160 \mathrm{~h}$.

\subsubsection{BR method}

The sensors obtained by basic routes were prepared from an ethanolic solution of the acid-base indicator AL, to which the catalyst $\mathrm{NH}_{4} \mathrm{OH}$ and TEOS were added under stirring at room temperature. The resulting solution was further stirred up to precipitation, followed by one additional hour, totalizing $1 \mathrm{~h}$ and $15 \mathrm{~min}$.

\subsubsection{NHR method}

For the non-hydrolytic route, all procedures were carried on under inert atmosphere. First, the catalyst and the indicator were put in contact, followed by the addition of TEOS and $\mathrm{SiCl}_{4}$. The resulting solution was stirred at $80{ }^{\circ} \mathrm{C}$ up to gelation (ca. $2 \mathrm{~h}$ ).

All solids were milled, washed with water and ethanol and then dried at $110{ }^{\circ} \mathrm{C}$ for $12 \mathrm{~h}$ (Scheme 2). For each route, a corresponding blank (silica without the encapsulation of $\mathrm{AL}$ ) was prepared [16].

Hereafter, the resulting sensors are labeled according to the sol-gel route. AL stands for alizarin red. For instance, ALNHR refers to the sensor prepared by non-hydrolytic route, containing alizarin red as the indicator.<smiles>O=C1c2ccccc2C(=O)c2c1cc(S(=O)(=O)[O-])c(O)c2O</smiles>

a) Alizarin Red S<smiles>O=C1c2ccccc2C(=O)c2c1ccc(O)c2O</smiles>

b) Alizarin Red

Scheme 1. Alizarin red S (a) and alizarin red (b) chemical structures. 

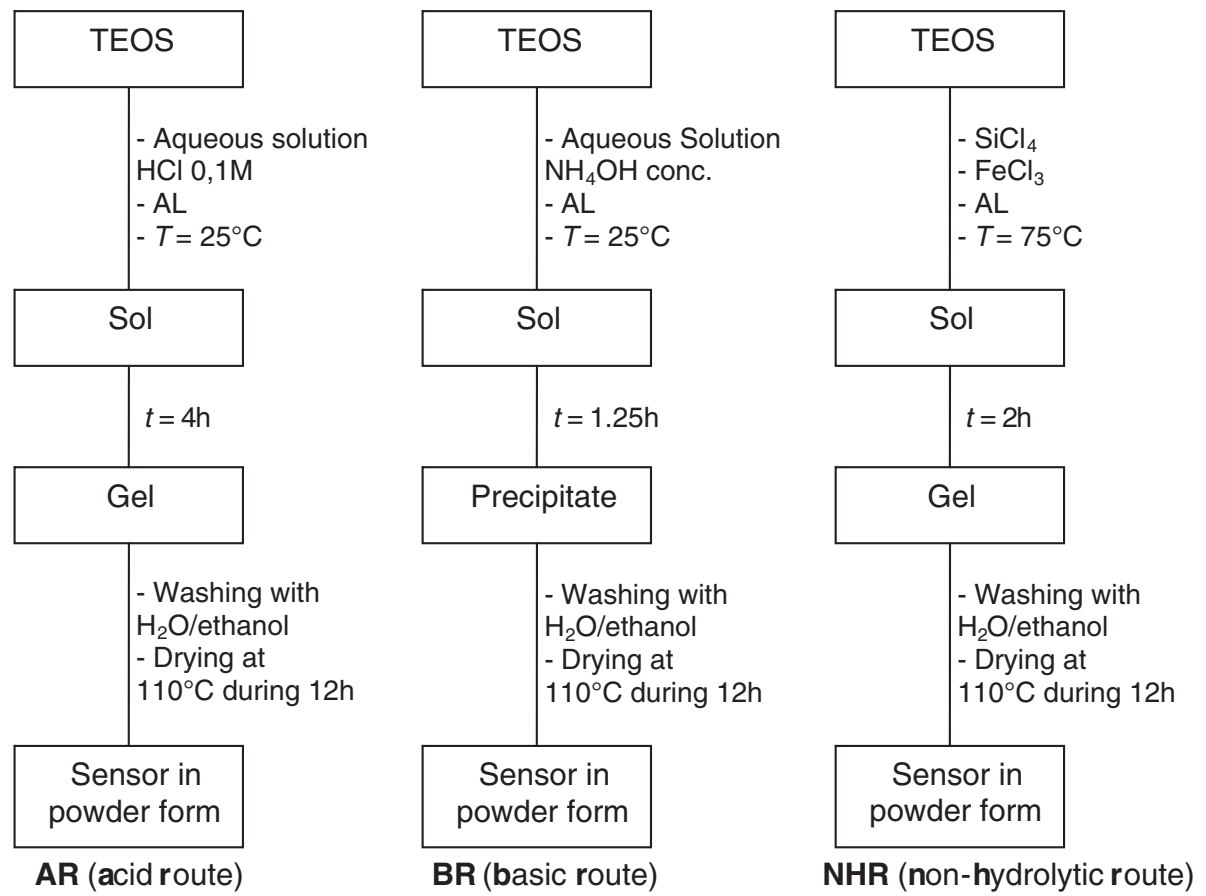

Scheme 2. The different sol-gel routes employed for sensor synthesis

\subsection{Cyclic voltammetry and differential pulse voltammetry}

Cyclic voltammetry (CV) and differential pulse voltammetry (DPV) measurements were carried on a potentiostat/galvanostat (PARC, model 273) using a conventional three electrode cell. The modified graphite electrode with an exposed surface area $S=0.152 \mathrm{~cm}^{2}$ and glassy carbon $\left(S=0.082 \mathrm{~cm}^{2}\right)$ were used as the working electrode. The working modified electrode consisted of the PVC body containing a graphite disk, which supported the carbon paste. Carbon paste was prepared by mixing high purity graphite and the modified silica with alizarin red in an 8:2 $(w / w)$ ratio with a drop of mineral oil. $\mathrm{Ag} / \mathrm{AgCl}$ was used as the reference electrode and platinum wire as the auxiliary one. All measurements were carried on under high purity argon. DPV experiments were performed using two media to support the electrolytes: (i) $0.1 \mathrm{~mol} \mathrm{~L}^{-1} \mathrm{NaBF}_{4}$ solutions with $\mathrm{pH}=1$ and (ii) BrittonRobinson (BR) buffer prepared by combining acetic acid, phosphoric acid and boric acid at $0.1 \mathrm{~mol} \mathrm{~L}^{-1}$. The $\mathrm{pH}$ of the BR buffer solution was adjusted by adding $\mathrm{NaOH}$ solution $\left(1 \mathrm{~mol} \mathrm{~L}^{-1}\right.$ and $\left.0.5 \mathrm{~mol} \mathrm{~L}^{-1}\right)$ and measured potentiometrically.

\subsection{Photoacoustic spectroscopy analysis}

A spectrometer manufactured by Optical Properties Laboratory (Physical Institute of UFBA, Brazil) was employed. This instrument bears a halogen lamp ( $250 \mathrm{~W} / 24 \mathrm{~V})$ source, mounted at the focus of a concave mirror that projects the filament image into a collimator slit-convergent lens set, generating a parallel beam. The white or polychromatic beam is sent to the monochromator, which is composed of a grating, convergent lens, collimator and output slit. The monochromatic light that emerges from the collimator is intersected by a chopper-type mechanical modulator (SR540 by Stanford) at a frequency of $24 \mathrm{~Hz}$. The grating angular position is related to the selected wavelength, and it is determined by a stepper motor and controlled by a purchase and control software. At the end of each mechanical step, the analogical information provided by the light sensors and detected by the SR540 lock-in amplifiers (Stanford Research) is acquired and stored by a personal computer. The spectra were collected in the $300-1800 \mathrm{~nm}$ range.

\subsection{Diffuse Reflectance Spectroscopy (DRS)}

UV-vis spectra of sensors in powder form were obtained on a Cary 100 UV-vis Spectrophotometer using the diffuse reflectance accessory. The $\mathrm{pH}$ indicator content was investigated by UV-DRS employing the standard-addition analytical method and all the calibration curves have showed linear correlation ( $r$ ) higher than 0.99 .

\section{Results and discussion}

\subsection{Voltammetric studies}

The cyclic voltammetry and differential pulse voltammetry were employed to evaluate the alizarin red sensors' behavior. The curves shape showed different peak potentials, depending on the route, which values were dependent on the $\mathrm{pH}$ and therefore, these materials could be used as $\mathrm{pH}$ sensors. For evaluating the alizarin red presence in the sensors prepared by sol-gel processes, the cyclic voltammogram profiles of the corresponding aqueous solution were also registered. Fig. 1 shows the cyclic voltammograms run in the potential range from 1 to $-0.7 \mathrm{~V}$ versus $\mathrm{Ag} / \mathrm{AgCl}$ at a potential scan rate at $100 \mathrm{mV} \mathrm{s}^{-1}$. When the potential sweep begins at $0 \mathrm{~V}$ and goes toward positive potential (continuous line in Fig. 1) or negative potential (broken line in Fig. 1 ), depicting pair peaks $E_{\mathrm{pc} 1} / E_{\mathrm{pa} 1}, E_{\mathrm{pc} 2} / E_{\mathrm{pa} 2}$ and anodic peak $E_{\mathrm{pa} 3}$. The curve profiles indicate that the pair peaks signals are independent. However, it was possible to assign the $E_{\mathrm{pa}}$ anodic current increase to a redox process involving a product formed after the AL reduction. Therefore, the dye reduction is followed by a coupled chemical reaction, similar to the behavior described in the literature [21].

To confirm the occurrence of a chemical reaction after AL reduction, a more negative potential than that of cathodic peak $\left(E_{\mathrm{pc} 2}\right)$ as $-350 \mathrm{mV}$ was applied. The results indicated that a cathodic current decrease in the $E_{\mathrm{pc} 1}$ and an increase in $E_{\mathrm{pa} 2}$ over time was evident (Fig. 2). The cyclic voltammogram shows an anodic peak $\left(E_{\mathrm{pa} 1}\right)$ at $+830 \mathrm{mV}$ and a corresponding cathodic peak of low intensity. The result is consistent with a reversible electrode process followed by a chemical reaction. According to the literature, the alizarin red undergoes a reversible reduction of the 


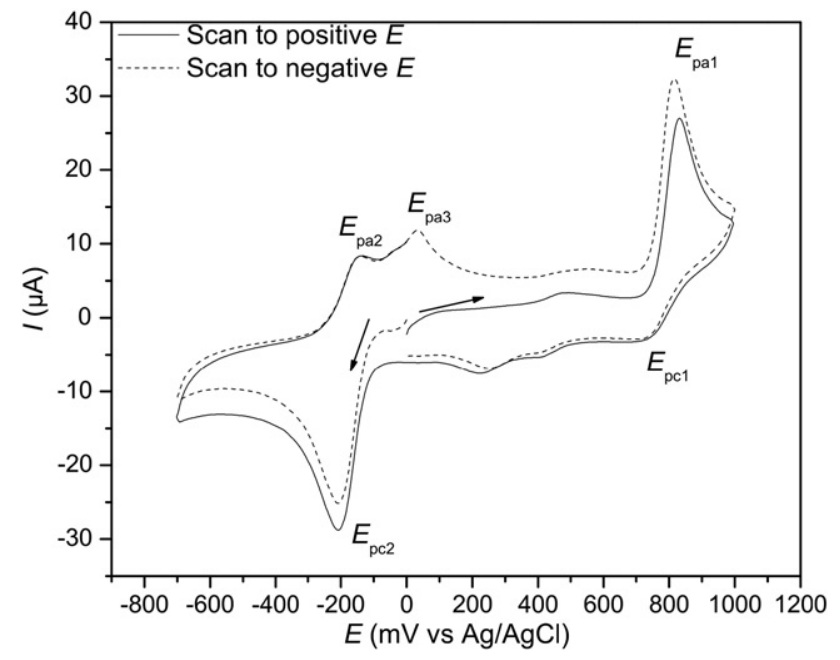

Fig. 1. Cyclic voltammograms of alizarin red (AL). Conditions: $1 \times 10^{-3} \mathrm{~mol} \mathrm{~L}^{-1}$ in $\mathrm{pH}=1$ $\mathrm{NaBF}_{4}$ solution $\left(v=100 \mathrm{mV} \mathrm{s}^{-1}\right)$. ( ) Scan to positive $E$ and (--) scan to negative $E$.

9,10-quinone form, resulting in a semiquinone, which can lead to a product containing the 1,2-dihydroxy moiety and a irreversibility of the oxidation, that change AL to 1,2 dioxoantraquinone (Scheme 3). In cyclic voltammetry studies on $\mathrm{AL}$ at $\mathrm{pH}=1.12$ a negative potential at $-0.245 \mathrm{~V}$ versus SCE (saturated calomelane electrode) was assigned to an irreversible redox process and $+0.722 \mathrm{~V}$ an irreversible redox process $[18,19,21]$.

Nevertheless, in this study, the differential pulse voltammogram (DPV) presented cathodic peaks with a corresponding anodic one that, in conjunction with the cyclic voltammetry profiles, suggests a reversible process with a coupled chemical reaction.

Zittel and Florence observed that both the alizarin red S (the sodium alizarin-3-sulfonate, i.e., the same indicator $(\mathrm{AL})$ but containing a sulfonic group) reduction potential to the 1,2-dihydroxyanthraquinone-9, 10-diol-3-sulfonate and the oxidation potential corresponding to the redox process leading to 1,2-dioxoanthraquinone-9,10-dione-3sulphonate formation are $\mathrm{pH}$ dependent [21]. In the present work, similar behavior was observed for alizarin red by both cyclic and differential pulse voltammograms. The waves at $E_{\mathrm{pc} 1} / E_{\mathrm{pa} 1}$ can be assigned 1,2-dihydroxyanthraquinone $(\mathrm{AL})$ to 1,2-dioxoanthraquinone process (Scheme 3). The AL curve shape for current versus potential in aqueous solution $\mathrm{pH}=9$ showed that the $E_{\mathrm{pa} 1}$ anodic signal has low intensity and the $E_{\mathrm{pa} 3}$ signal has a prominent intensity when compared to the cyclic

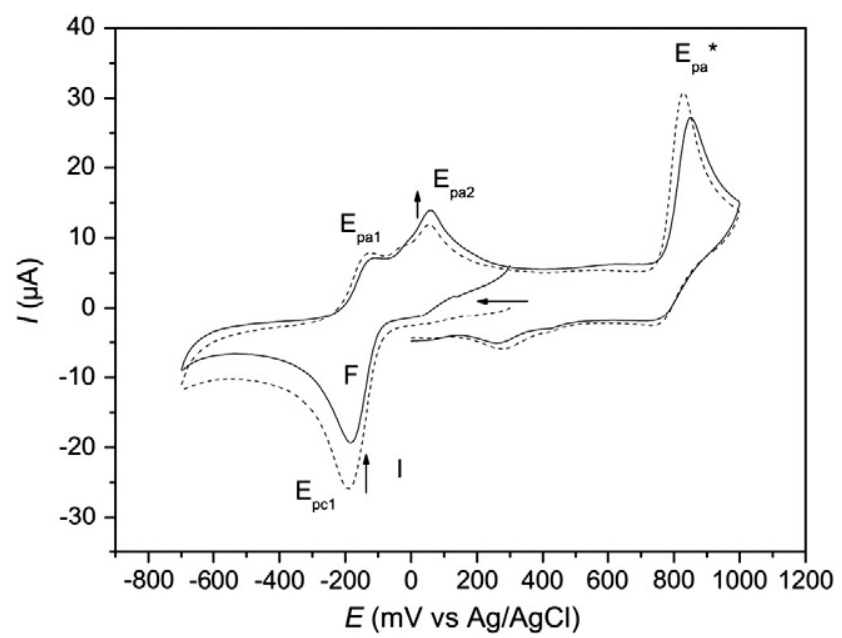

Fig. 2. Cyclic voltammograms of alizarin red (AL). Conditions: $1 \times 10^{-3} \mathrm{~mol} \mathrm{~L}^{-1}$ in $\mathrm{pH}=1$ $\mathrm{NaBF}_{4}$ solution $\left(v=100 \mathrm{mV} \mathrm{s}^{-1}\right)$. Initial curve ( ) and after the applied potential (---). $\left(\mathrm{E}_{\text {applied }}=-350 \mathrm{mV}\right)$. voltammogram shape in acid aqueous solution. These results indicate that the chemical reaction is $\mathrm{pH}$ dependent, and the signal shifts support the use of $\mathrm{AL}$ as a potential $\mathrm{pH}$ sensor.

Fig. 3 shows differential pulse voltammograms (DPV) profiles of $\mathrm{AL}$ aqueous solutions within the 1 to $8 \mathrm{pH}$ range. Compared to the cyclic voltammogram results (Fig. 1) with the DPV curves, both DPV profiles registered at $\mathrm{pH}=1$ show that the same cathodic or anodic peaks slightly shifted, probably due to a coupled chemical reaction. Reduction and oxidation reactions of $\mathrm{AL}$ are dependent on the $\mathrm{H}_{3} \mathrm{O}^{+}$ ion involvement (Scheme 3). This assumption can be confirmed by the relative detected potential value analysis.

Fig. 3 shows that $E_{\mathrm{pc} 1}$ (cathodic peaks at positive potential and high intensity current) and $E_{\mathrm{pc} 2}$ (cathodic peaks at negative potential and high intensity current) signals are shifted toward less positive and more negative values, respectively, as well as the corresponding anodic peaks, with $\mathrm{pH}$. The signal shifts in function $\mathrm{pH}$ were also illustrated in DPV profiles with anodic scans. The chemical reaction rates occurring on the electrode surface (Scheme 3), which is not the objective of the present study, are also $\mathrm{pH}$ dependent. As the peak shifts with the $\mathrm{pH}$, the reaction rate can also be altered, changing the peak current intensity. For example, in $\mathrm{pH}=2$, the peak intensity is higher than those in $\mathrm{pH}=1$ and 3 . This behavior may indicate that in $\mathrm{pH}=2$ there shall be contribution of the electroactive species to the peak potential and current intensity.

In pursuit of information about behavior of AL by DPV, analysis of the data obtained for the cathodic peaks $E_{\mathrm{pc} 1}-\mathrm{pH}$ and $E_{\mathrm{pc} 2}-\mathrm{pH}$ plots show a linear correlation and a slope of $59 \mathrm{mV}$ (Fig. 4). The same behavior was observed in the case of anodic waves. According to Scheme 3, alizarin red reduction $\left(E_{\mathrm{pc} 2}\right)$ requires two electrons to allow the generation of 1,2-dihydroxyanthracene-9,10-diol. According to the literature, the oxidation to 1,2-dioxoanthracene-9,10-dione also involves two electrons [21]. Thus, the cathodic peaks illustrated in Fig. 3 could be associated to alizarin red reduction $\left(E_{\mathrm{pc} 2}\right)$ and to 1,2-dioxoanthracene-9,10-dione reduction $\left(E_{\mathrm{pc} 1)}\right.$ that, according to the Nernst equation analysis [29], and assuming that the concentration ratio between oxidized and reduced species is equal, it can be assumed that $E_{\mathrm{p}} / \mathrm{pH}$ is equal to a $0.059 x / n$ ratio. It is worth explaining that in this equation, $x$ and $n$ refer to the number of $\mathrm{H}_{3} \mathrm{O}^{+}$ions and the electron number, respectively involved in reduction or oxidation process of electroactive species. Thus, the results $E_{\mathrm{pc} 1}$ and $E_{\mathrm{pc} 2}$ in function of $\mathrm{pH}$ (Fig. 4) may indicate the same number of electrons and protons, for both redox processes which corresponds to two.

The results obtained to the aqueous solutions were very important for the analysis of the encapsulated alizarin voltammograms' shape. From the sample of the encapsulated alizarin red obtained by the acid route (ARAL), the DPV shows cathodic peaks with corresponding anodic waves, which are related to the $\mathrm{pH}$ indicator redox processes, confirming AL presence within the silica matrices. This behavior was also verified in the other samples: alizarin red obtained by the basic route (BRAL), alizarin red obtained by the non-hydrolytic route (NHRAL) and alizarin red obtained by non-catalyzed route (NCRAL). Fig. 5 shows DPV with cathodic potential scanning for the modified electrode with silica-sensors. The sample synthesized without the $\mathrm{pH}$ indicator, i.e., the bare silica matrices, did not show signals in this potential range.

As in the case of free AL, the DPVs for the modified electrode with ARAL indicated that the anodic and cathodic peaks are dependent on the $\mathrm{pH}$ but had different values than the free (neat) indicator. These results can provide some insights into the interactions between the silica and indicator. The ARAL DPV in $\mathrm{pH}=1$ produces a cathodic peak at $+480 \mathrm{mV}$ versus $\mathrm{Ag} / \mathrm{AgCl}$, which has a corresponding anodic signal at a less positive potential with a low intensity in free AL, and it can be related to the indicator-silica interaction. This pair of peaks (cathodic and anodic) is not observed by increasing pH (Fig. 6). Because these peaks are related with $\mathrm{AL}$ oxidation, resulting in 1,2-dioxoanthracene-9,10-dione, the electrochemical process has to 


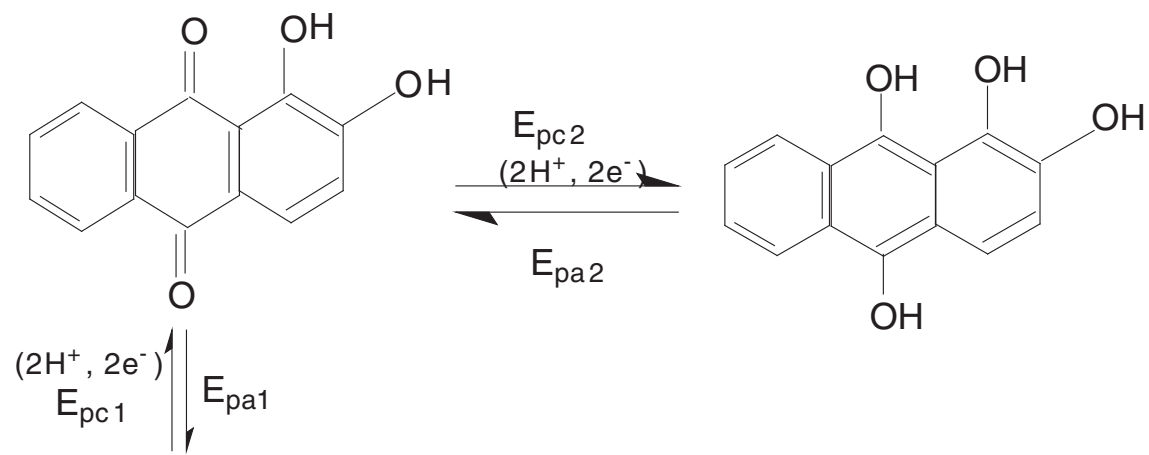<smiles>O=c1ccc2c(=O)c3ccccc3c(=O)c=2c1=O</smiles>

Scheme 3. Oxidation and reduction electrochemical processes for alizarin red.

involve vicinal $\mathrm{OH}$ groups. Therefore, it may be proposed that the interaction between the silica and indicator takes place through silanol groups (Scheme 4).

The ARAL sensor also showed potential shifts in the anodic peaks values, and they presented a linear correlation between the peak potential and the $\mathrm{pH}$. The anodic peak at positive potential $\left(E_{\mathrm{pa} 1}\right)$ analysis (AL oxidation) as a function of $\mathrm{pH}$ results in a slope value of approximately $30 \mathrm{mV}$, indicating a process that implicates two electrons and one proton. This behavior suggests a possible interaction of silica-indicator by the $\mathrm{OH}$ groups. The cathodic peaks (potential at negative values) in DPV (AL reduction) as a function of $\mathrm{pH}$ involved a two proton and two electron processes, as in the case of the free indicator analysis.

In the case of the BRAL sensor, the cathodic peaks $\left(E_{\mathrm{pc} 1}\right)$ present low intensity current if compared to that of ARAL that were found at $\mathrm{pH}=1$ and $\mathrm{pH}=2$ (BR buffer solution). Furthermore, for $\mathrm{pH}=1$, a cathodic peak at $+390 \mathrm{mV}$ versus $\mathrm{Ag} / \mathrm{AgCl}$, whose redox process can be attributed to the same process ascribed to oxidation ARAL at $\mathrm{pH}=1$, is detected. The DPV shape in the case of $\mathrm{pH}=2$ shows a cathodic peak around $+212 \mathrm{mV}$ versus $\mathrm{Ag} / \mathrm{AgCl}$ (Fig. 7). According to

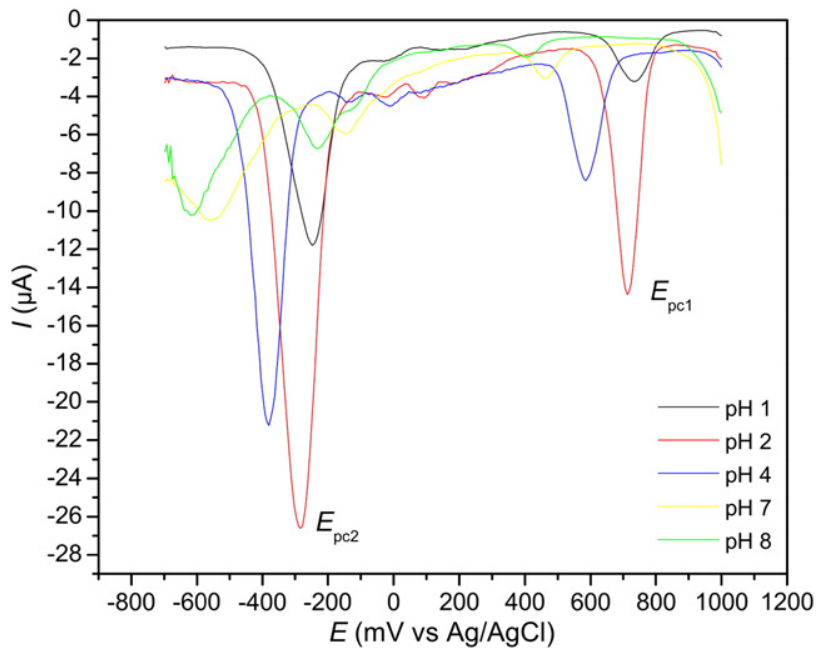

Fig. 3. DPV of AL $1 \times 10^{-3} \mathrm{~mol} \mathrm{~L}^{-1}$ in BR buffer aqueous solution $\left(v=100 \mathrm{mV} \mathrm{s}^{-1}\right)$. Cathodic scan in solution with pH from 1 to 8 . the BRAL DPV profile, a potential shift in the AL reduction and oxidation processes is observed compared to ARAL and free AL in solution.

For this sensor (BRAL), redox processes related to the AL indicator were also identified, with an oxidation process around $+390 \mathrm{mV}$ versus $\mathrm{Ag} / \mathrm{AgCl}$ in $\mathrm{pH}=1$ and a reduction process at $-180 \mathrm{mV}$ versus $\mathrm{Ag} / \mathrm{AgCl}$. The relative potential value also indicates $\mathrm{pH}$ dependence, as observed in the case of ARAL and AL. Moreover, different numbers of cathodic and anodic peaks were found, depending on the $\mathrm{pH}$ value. With the potential relative value analysis and the potential versus $\mathrm{pH}$ curve slopes, it was possible to prove that the cathodic and anodic processes were not corresponding processes. This behavior suggests different redox processes beyond those proposed for alizarin red oxidation and reduction depicted in Scheme 3.

Table 1 shows the potential versus $\mathrm{pH}$ linear correlations of each peak of the BRAL sensor. According to the Nernst equation [29] the $0.059 x / n$ ratio results in a different number of protons and electrons in each process when compared to the other sensors. The results were different from those concerning the material prepared by acid route, for example. These results were related to the change of silica-dye interactions, to the formation of more than one product during the

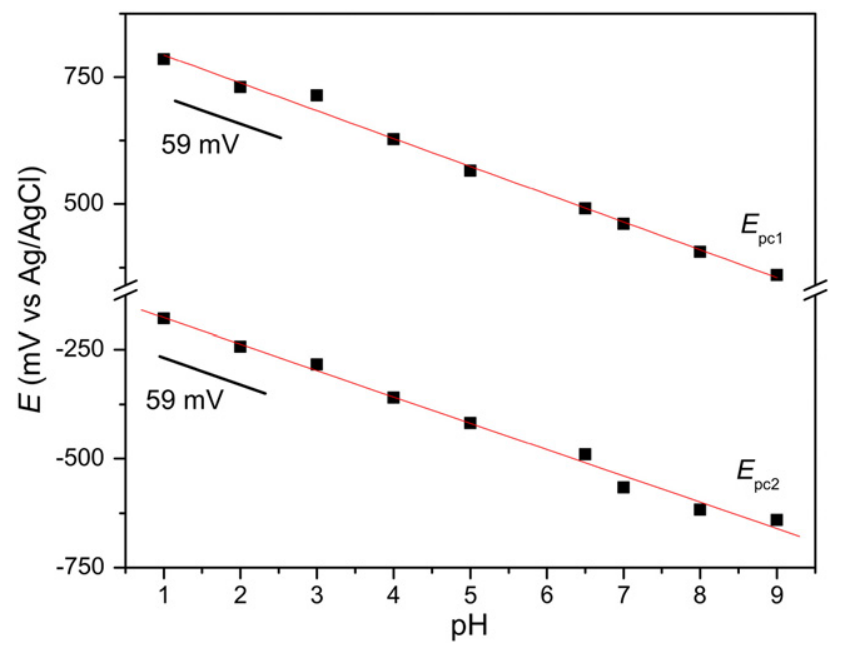

Fig. 4. Linear correlation between $E_{\mathrm{pc} 1}$ and $E_{\mathrm{pc} 2}$ versus $\mathrm{pH}$ with slope of $59 \mathrm{mV}$. 


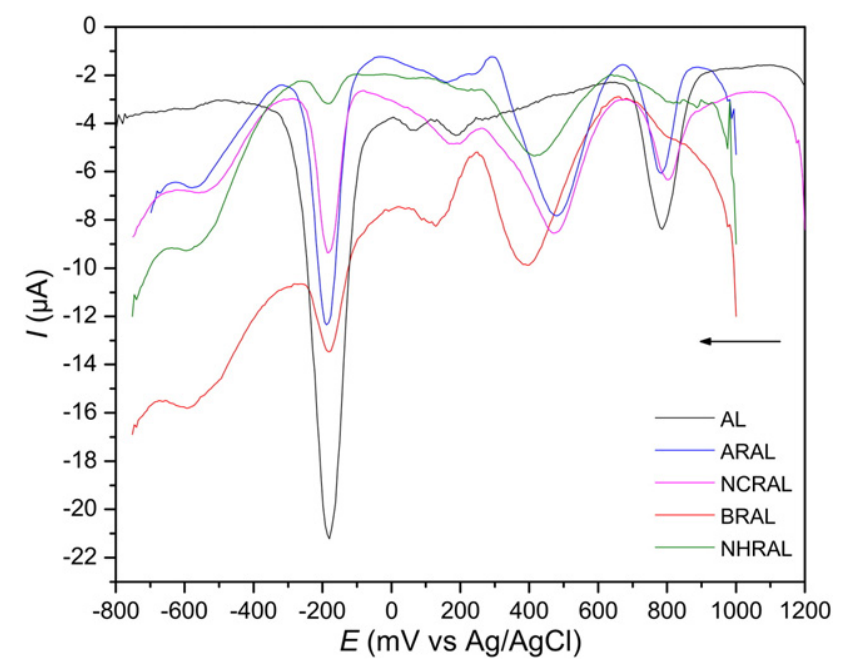

Fig. 5. DPV to AL and modified electrode to ARAL, BRAL, NHRAL and NCRAL in BR buffer aqueous solution with $\mathrm{pH}=7$. Cathodic scan with $v=100 \mathrm{mV} \mathrm{s}^{-1}$.

chemical reactions of the material preparation and to the chemical reactions on the electrode surface during the cathodic/anodic scans. In other words, in the BRAL material a higher number of products were observed, resulting from the silica-dye interactions, from the material preparation and from reactions on the electrode surface.

In the case of the NHRAL sensor, in $\mathrm{pH}=1$, the cathodic signal attributed to the indicator oxidized form around $+790 \mathrm{mV}$ versus $\mathrm{Ag} / \mathrm{AgCl}$ presents a low intensity signal if compared to the cathodic wave in DPV to ARAL. This behavior is probably due to the alizarin red quinone to dioxoanthracene conversion (Scheme 1) under synthetic conditions. In addition, the NHRAL curve profile is similar to that of ARAL, which suggests that the silica-indicator interaction in these materials may be similar. The anodic signals at positive potential illustrate peak current relative intensities, which were different from those of the ARAL and BRAL materials. This behavior may contribute to the consumption of the indicator in its quinone form during the NHRAL preparation. The redox process $E_{\mathrm{pa} 1} / E_{\mathrm{pc} 1}$, in this case, was shifted from $+450 \mathrm{mV}(\mathrm{pH}=1)$ to $+3 \mathrm{mV}($ at $\mathrm{pH}=5$ ) (Fig. 8) which is probably due to different species of AL in the original one. These results indicate that the redox process is very dependent on $\mathrm{pH}$, as it was observed in the case of the AL reduction and oxidation reactions (Scheme 1). Therefore, for the $\mathrm{pH}=6$ solution, no well-defined

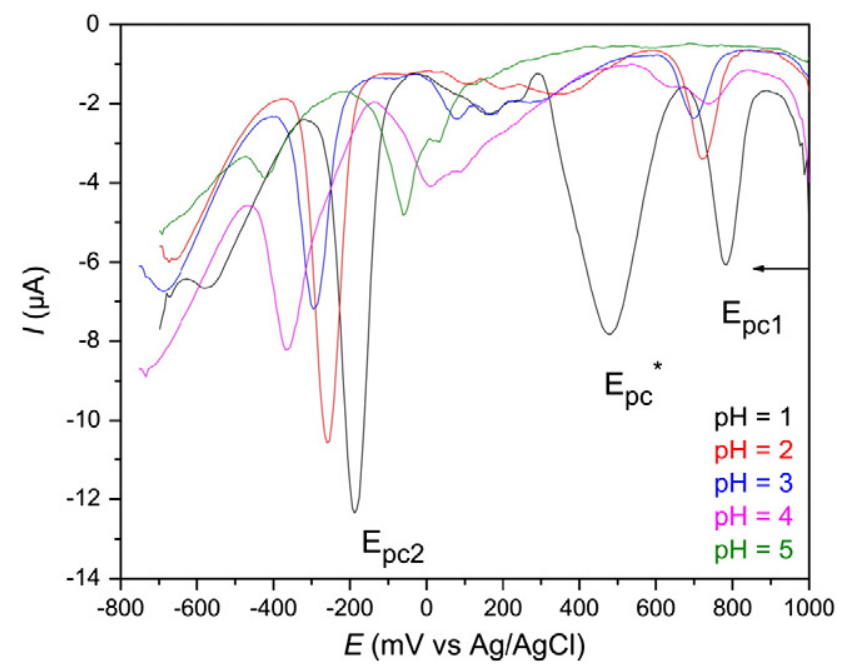

Fig. 6. DPV to AL and modified electrode to ARAL in BR buffer aqueous solution with $\mathrm{pH}=1$ to 5 . Cathodic scan with $v=100 \mathrm{mV} \mathrm{s}^{-1}$.

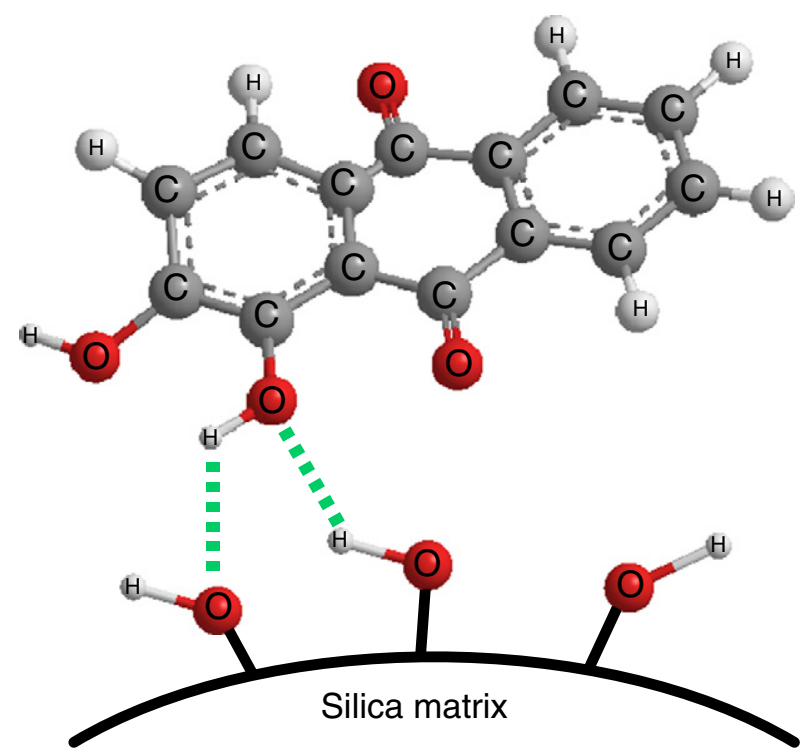

Scheme 4. The proposed interaction between silica and alizarin red.

anodic and cathodic waves could be detected, therefore limiting study in a broader $\mathrm{pH}$ range.

Finally, in the case of the sensor obtained by the hydrolytic sol-gel route without catalyst (NCRAL) (Fig. 9), a behavior similar to that found for ARAL was observed: the same number of cathodic and anodic signals but slightly differing in current intensity. This result suggests that whether the indicator might be similarly interacting with silica or the quinone conversion into another species (as semiquinone), it presents a similar reaction rate. The NCRAL also exhibited changes in anodic and cathodic peaks with potential values as a function of $\mathrm{pH}$. A linear correlation between the peak potential and $\mathrm{pH}$ was verified with a slope of $56 \mathrm{mV}$ to $E_{\mathrm{pc} 2}$ (cathodic peaks at negative potential) and $40 \mathrm{mV}$ to $E_{\mathrm{pa} 1}$ (anodic peaks at positive potential). The $E_{\mathrm{pc} 2}$ result indicates a process involving two electrons and two protons (see Scheme 3), similar to the case of ARAL. For $E_{\mathrm{pa} 1}$, the ARAL presented a slope of $30 \mathrm{mV}$, corresponding to a process with one proton and two electrons, which was consistent with an indicator-silica interaction through vicinal $\mathrm{OH}$ groups (Scheme 4). Similar to ARAL, it can be proposed that the NCRAL silicaindicator interactions occur by the same groups, justifying the redox process approximation to two electrons and one proton involvement.

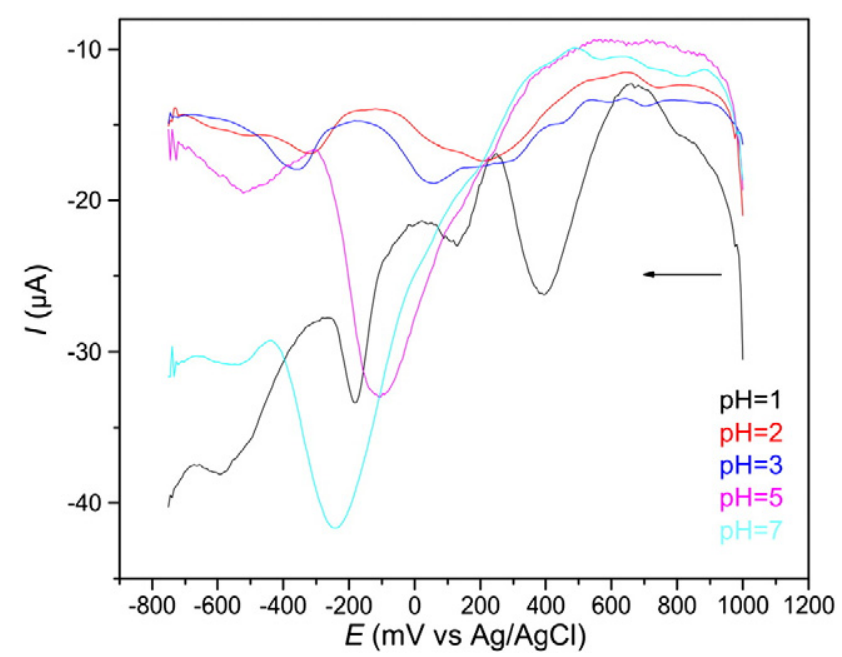

Fig. 7. DPV to AL and modified electrode to BRAL in BR buffer aqueous solution with $\mathrm{pH}=1$ to 7 . Cathodic scan with $v=100 \mathrm{mV} \mathrm{s}^{-1}$. 
Table 1

Slope values of $E_{\mathrm{p}}$ vs pH curves and the x (number of $\mathrm{H}_{3} \mathrm{O}^{+}$ions) and $\mathrm{n}$ (number of electrons) for the AL in BRAL sensor.

\begin{tabular}{lccc}
\hline Curves & Slope $(\mathrm{mV})$ & $\mathrm{x}$ & $\mathrm{n}$ \\
\hline$E_{\mathrm{pc} 1} \times \mathrm{pH}$ & 113 & 2 & 1 \\
$E_{\mathrm{pc} 2} \times \mathrm{pH}$ & 74 & 5 & 4 \\
$E_{\mathrm{pa} 1} \times \mathrm{pH}$ & 76 & 5 & 4 \\
$E_{\mathrm{pa} 2} \times \mathrm{pH}$ & 52 & 2 & 2 \\
& 52 & 1 & 1 \\
\hline
\end{tabular}

According to Fig. 5, the DPV curves of the modified electrodes with the AL encapsulated sensors obtained by the different routes show anodic and cathodic processes related to the AL indicator bearing different relative intensities. This behavior is in agreement with the indicator conversion into different species as a function of the $\mathrm{pH}$ of the medium.

These results were further confirmed by photoacoustic spectroscopy (PAS) in the UV-vis region, as shown in Fig. 10, in which the maximum band positions assigned to AR were shifted depending on route. Generally, the maximum band position of a molecule on the surface of a solid can be affected by several factors, such as steric effects, medium polarity, hydrogen bond and surface acidity [30]. For all the routes, a hypsochromic shift (blue shift) could be observed for AL. This behavior can be explained by an increase in the polarity of the medium because the indicator may interact with the silanol groups of silica surface. In this situation, molecules bearing $n-\pi^{*}$ type transitions, as with alizarin red, lead to hypsochromic shifts [30]. For the AR and NCR routes similar results were observed. This behavior could be explained by considering a similar mechanism, since the AR is slightly acid and affords acidity in the reaction medium. For the NHR sensor, residues of the catalyst $\left(\mathrm{FeCl}_{3}\right)$ are still present within the silica matrix and this may cause the broadening of the peak, since the AL could also coordinate to the Fe moieties. Finally, for the BR sensor, no bands could be detected for AL, probably due to the low amount $\left(0.13 \mathrm{mg} \mathrm{g}^{-1}\right)$ of encapsulated indicator.

These results were related with the sensor performance already shown in a previous paper [16]. In this work, the acid route with the shortest response time (59 s) and the non-hydrolytic route with a longer response time (149 s) were shown. For the basic route, it was impossible to measure the response time because it bore little encapsulated material. Comparing the previous performance results with the peaks potential showed in voltammetry studies, it is possible to propose an explanation of the performance behavior. Once the AR forms the less complex species during the sensor preparation, the

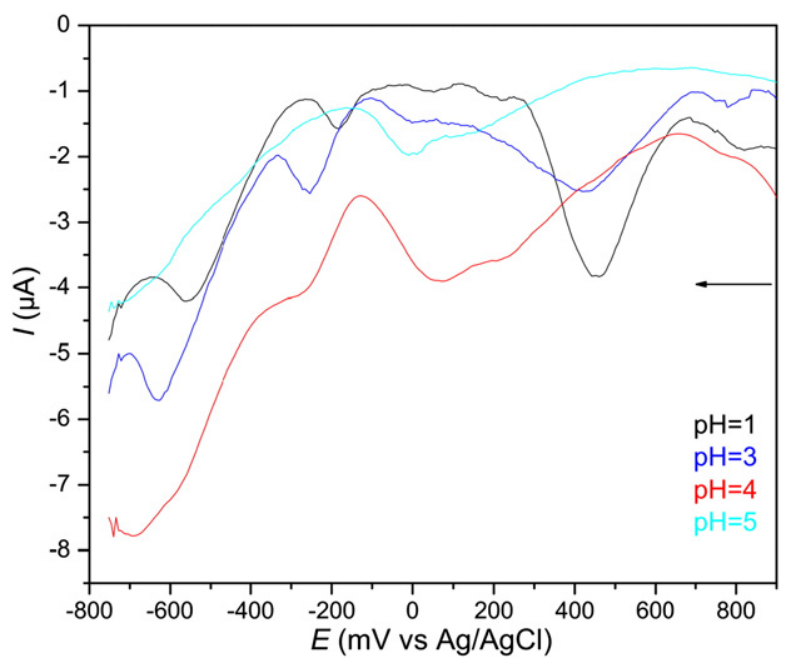

Fig. 8. DPV to AL and modified electrode to NHRAL in BR buffer aqueous solution with $\mathrm{pH}=1$ to 5 . Cathodic scan with $v=100 \mathrm{mV} \mathrm{s}^{-1}$.

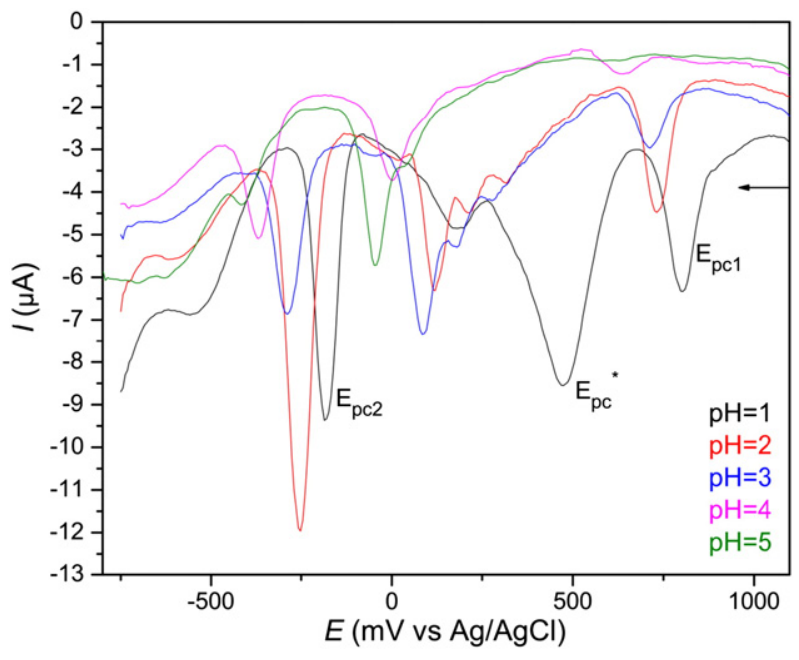

Fig. 9. DPV to AL and modified electrode to NCRAL in BR buffer aqueous solution with $\mathrm{pH}=1$ to 5 . Cathodic scan with $v=100 \mathrm{mV} \mathrm{s}^{-1}$.

indicator may be more available for the analyte identification reaction. In the same way, the NHR involved quinone consumption and the formation of another species during the sol-gel process, which may prevent the analyte access to an available indicator molecule in the silica network.

\subsection{Analytical data}

The amount of indicator contents was calculated from Diffuse Reflectance Spectroscopy in the ultraviolet-visible (UV-DRS) range, according to the methodology described elsewhere [31]. The results, already reported [16,31], were dependent on the employed route. It was only possible to detect measurable contents by UV-DRS in the acid and non-hydrolytic routes, which were $9.95 \mu \mathrm{mol} \mathrm{g}^{-1}$ and $7.99 \mu \mathrm{mol} \mathrm{g}^{-1}$, respectively. For NCR and BR routes, AL was only detected by the voltammetric techniques.

\subsubsection{Measurement range}

The tests of measurement range were performed with aqueous solutions, ammonia gas and real samples of galvanic baths as described elsewhere [32]. The tests have shown as the most suitable routes as the acid one and the non-hydrolytic one. To identify ammonia gas, the response time was about $60 \mathrm{~s}$. In the measurement of the $\mathrm{pH}$ in aqueous solutions, the most effective detection was from $\mathrm{pH}=1$

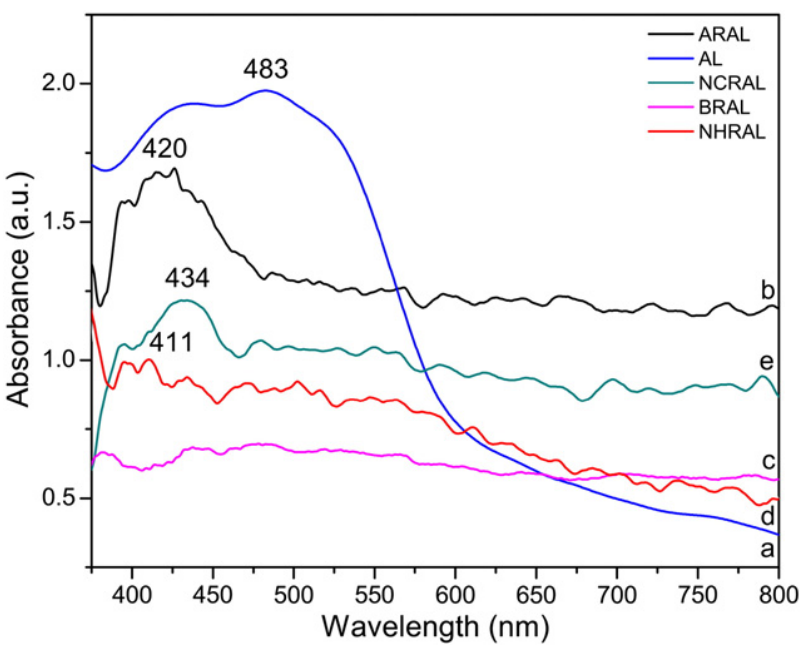

Fig. 10. PAS spectra in the UV-vis region for AL and the different sensors: bare AL (a), ARAL (b), BRAL (c), NHRAL (d), NCRAL (e). 
and 2 and higher than 9. In these ranges, it was possible to identify each unit of $\mathrm{pH}$.

\subsubsection{Reusing and life time}

An important parameter in real sample applications is reusing and the life time of the sensor, which in turn represents decreasing in analysis costs. Therefore, the sensors were investigated in terms of their reversibility (regeneration) and life time in stock. For the reusing tests, the sensors were exposed to ammonia gas and solutions with $\mathrm{pH}=14$. After exposition and color changes, the sensors were heated in order to recover them for a possible reusing. All the sensors were able of reusing and remained active after five tested cycles. The life time was tested after 1 year of stock and all the sensors remained working properly.

\section{Conclusions}

This study demonstrated the use of differential pulse voltammetry as a potential technique for investigating the possible interactions between alizarin red ( $\mathrm{pH}$ indicator) and a silica network, in order to develop a $\mathrm{pH}$ sensor. It was possible to identify reversible processes for both oxidation and reduction reactions that involved two electrons. For the sensor prepared by the acid-catalyzed and hydrolytic without catalyst routes, alizarin red was shown to interact with silica through the hydroxyl groups. In addition, for the basic route and the non-hydrolytic route, the synthetic route seems to influence the alizarin red electrochemical behavior. For the basic route, differently shaped waves were observed depending on the $\mathrm{pH}$, suggesting different silica-indicator interactions and/or the presence of other products formed during the material preparation or in the cathodic/anodic scans. For the non-hydrolytic route, the consumption of alizarin red in its quinone form during the process is proposed, although the interactions may occur through the same groups as in the acid route. Ultraviolet-visible photoacoustic spectrometry also proved that interactions with the silica networks occur, and spectral shifts were observed. Such results suggest the potential use of sol-gel routes in the development of $\mathrm{pH}$ sensors in the sense that one can tune the active molecule response to the analyte, depending on the nanostructurated generated species, which in turn allow the quest for a system with a broader $\mathrm{pH}$ response.

\section{Acknowledgments}

This project was partially financed by the FAPERGS/PRONEX and FAURGS-Braskem. L.B. Capeletti thanks the CNPq for the grant.

\section{References}

[1] T. Asefa, C.T. Duncan, K.K. Sharma, Recent advances in nanostructured chemosensors and biosensors, The Analyst 134 (2009) 1980-1990.

[2] S. Jurmanovic, S. Kordic, M.D. Steinberg, I.M. Steinberg, Organically modified silicate thin films doped with colourimetric $\mathrm{pH}$ indicators methyl red and bromocresol green as $\mathrm{pH}$ responsive sol-gel hybrid materials, Thin Solid Films 518 (2010) 2234-2240.

[3] A. Walcarius, M.M. Collinson, Analytical chemistry with silica sol-gels: traditional routes to new materials for chemical analysis, Annual Review of Analytical Chemistry 2 (2009) 121-143.

[4] J. Tan, H.F. Wang, X.P. Yan, Discrimination of saccharides with a fluorescent molecular imprinting sensor array based on phenylboronic acid functionalized mesoporous silica, Analytical Chemistry 81 (2009) 5273-5280.
[5] L.A. Terry, S.F. White, L.J. Tigwell, The application of biosensors to fresh produce and the wider food industry, Journal of Agricultural and Food Chemistry 53 (2005) 1309-1316.

[6] B.R. Eggins, Chemical sensors and biosensors, John Wiley \& Sons, Chinchester, 2002.

[7] H.X. Chen, X.D. Wang, X.H. Song, T.Y. Zhou, Y.Q. Jiang, X. Chen, Colorimetric optical $\mathrm{pH}$ sensor production using a dual-color system, Sensors and Actuators B: Chemical 146 (2010) 278-282.

[8] D. Wencel, B.D. MacCraith, C. McDonagh, High performance optical ratiometric sol-gel-based pH sensor, Sensors and Actuators B: Chemical 139 (2009) 208-213.

[9] O. Bunkoed, F. Davis, P. Kanatharana, P. Thavarungkul, S.P.J. Higson, Sol-gel based sensor for selective formaldehyde determination, Analytica Chimica Acta 659 (2010) 251-257.

[10] S. Fardindoost, A.I. Zad, F. Rahimi, R. Ghasempour, Pd doped $\mathrm{WO}_{3}$ films prepared by sol-gel process for hydrogen sensing, International Journal of Hydrogen Energy 35 (2010) 854-860.

[11] G. Maduralveeran, R. Ramaraj, Gold nanoparticles embedded in silica sol-gel matrix as an amperometric sensor for hydrogen peroxide, Journal of Electroanalytical Chemistry 608 (2007) 52-58.

[12] R. Ojani, E. Ahmadi, J.B. Raoof, F. Mohamadnia, Characterization of a carbon paste electrode containing organically modified nanostructure silica: application to voltammetric detection of ferricyanide, Journal of Electroanalytical Chemistry 626 (2009) 23-29.

[13] F. Yang, L.S. Jiao, Y.F. Shen, X.Y. Xu, Y.J. Zhang, L. Niu, Enhanced response induced by polyelectrolyte-functionalized ionic liquid in glucose biosensor based on sol-gel organic-inorganic hybrid material, Journal of Electroanalytical Chemistry 608 (2007) $78-83$.

[14] P.C.A. Jeronimo, A.N. Araujo, M. Montenegro, Optical sensors and biosensors based on sol-gel films, Talanta 72 (2007) 13-27.

[15] L.T. Arenas, D.S.F. Gay, C.C. Moro, S.L.P. Dias, D.S. Azambuja, T.M.H. Costa, E.V Benvenutti, Y. Gushikem, Brilliant yellow dye immobilized on silica and silica/titania based hybrid xerogels containing bridged positively charged 1,4-diazoniabicyclo [2.2.2]octane: preparation, characterization and electrochemical properties study, Microporous and Mesoporous Materials 112 (2008) 273-283.

[16] L.B. Capeletti, F.L. Bertotto, J.H.Z. Dos Santos, E. Moncada, M.B. Cardoso, The effect of the sol-gel route on the characteristics of acid-base sensors, Sensors and Actuators B: Chemical 151 (2010) 169-176.

[17] S.P. Kounaves, Voltammetric techniques, in: F.A. Settle (Ed.), Handbook of Instrumental Techniques for Analytical Chemistry, Prentice Hall, Hardcover, 1997.

[18] T. Ohsaka, N. Oyama, Y. Takahira, S. Nakamura, Charge-transport rates in polyelectrolyte films on electrodes: disparate diffusion coefficients for alizarin red S with two separate electroactive centers, Journal of Electroanalytical Chemistry 247 (1988) 339-343.

[19] J. Revenga, F. Rodriguez, J. Tijero, Study of the redox behavior of anthraquinone in aqueous-medium, Journal of the Electrochemical Society 141 (1994) 330-333.

[20] K. Yasukouchi, I. Taniguchi, H. Yamaguchi, K. Arakawa, Anodic-oxidation of acridine in acetonitrile, Journal of Electroanalytical Chemistry 121 (1981) 231-240.

[21] H.E. Zittel, T.M. Florence, Voltammetric and spectrophotometric study of the zirconium-alizarine Red S complex, Analytical Chemistry 39 (1967) 320-326.

[22] C.d.S. Alfenas, G.P. Ricci, E.H. de Faria, M. Saltarelli, O.J. de Lima, Z.N. da Rocha, E.J. Nassar, P.S. Calefi, L.B. Montanari, C.H. Gomes Martins, K.J. Ciuffi, Antibacterial activity of $\mathrm{Nb}$-aluminum oxide prepared by the non-hydrolytic sol-gel route, Journal of Molecular Catalysis A: Chemical 338 (2011) 65-70.

[23] A. Fisch, C.F. Petry, D. Pozebon, F.C. Stedile, N.S.M. Cardozo, A.R. Secchi, J.H.Z dos Santos, Immobilization of zirconocene into silica prepared by non-hydrolytic sol-gel method, Macromolecular Symposia 245-246 (2006) 77-86.

[24] U. Schubert, N. Hüsing, Synthesis of Inorganic Materials, Wiley, Weinheinm, 2005

[25] L. Bourget, R.J.P. Corriu, D. Leclercq, P.H. Mutin, A. Vioux, Non-hydrolytic sol-gel routes to silica, Journal of Non-Crystalline Solids 242 (1998) 81-91.

[26] J.N. Hay, H.M. Raval, Preparation of inorganic oxides via a non-hydrolytic sol-gel route, Journal of Sol-Gel Science and Technology 13 (1998) 109-112.

[27] M.D. Curran, A.E. Stiegman, Morphology and pore structure of silica xerogels made at low pH, Journal of Non-Crystalline Solids 249 (1999) 62-68.

[28] W. Stober, A. Fink, E. Bohn, Controlled growth of monodisperse silica spheres in micron size range, Journal of Colloid and Interface Science 26 (1968) 62-69.

[29] A.J. Bard, L.R. Faulkner, Electrochemical Methods: Fundamentals and Applications, John Wiley \& Sons, New York, 1980.

[30] C.N.R. Rao, Ultraviolet and Visible Spectroscopy, Butter-worth, London, 1975.

[31] L.B. Capeletti, J.H.Z. dos Santos, E. Moncada, Quantification of indicator content in silica-based $\mathrm{pH}$ solid sensors by diffuse reflectance spectroscopy, Analytical Methods 3 (2011) 2416-2420.

[32] L. Capeletti, J. Dos Santos, E. Moncada, Dual-target sensors: the effect of the encapsulation route on $\mathrm{pH}$ measurements and ammonia monitoring, Journal of Sol-Gel Science and Technology (2012) 1-10. 